\title{
Cardiorespiratory evaluation of juvenile rats experimentally envenomed with
}

\section{Tityus serrulatus venom}

\author{
Pinto MCL (1), Melo MB (1), Cruz ML (1), Verçosa Junior D (1), Melo MM (1)
}

(1) School of Veterinary Medicine, Federal University of Minas Gerais, UFMG, Belo Horizonte, Minas Gerais State, Brazil.

\begin{abstract}
Accidental envenomation caused by Tityus serrulatus scorpions is very common in Brazil and may result in serious cardiorespiratory alterations that are frequently fatal to children. In the present study, the effects of $T$. serrulatus venom on the cardiorespiratory system of recently weaned male Wistar rats were evaluated. Fifteen animals were distributed into three groups $(n=5)$. The control group $\mathrm{A}$ received $400 \mu \mathrm{L}$ ultrapure water by subcutaneous injection, while the experimental groups $B$ and $C$ were injected with scorpion venom (100 and $450 \mu \mathrm{g}$, respectively, in $400 \mu \mathrm{L}$ water). Electrocardiogram (ECG) traces were obtained prior to the experiment, at five-minute intervals up to 30 minutes after treatment. At 40 minutes after envenomation, the animals had severe acute symptoms and were subsequently anesthetized for blood collection by means of intracardiac puncture. Biochemical profiles for the cardiac muscle were established by colorimetric analysis of creatine kinase (CK) and CK-MB isoenzyme. Semiquantitative analysis of troponin was performed using the immunochromatographic assay. Following euthanasia, the lungs and hearts were removed and subjected to histopathological examination. All experimental animals had ECG alterations compatible with electrolytic imbalance, myocarditis and alterations of the cardiac conduction system. Envenomed animals had accentuated bradycardia at 25 and 30 minutes after venom inoculation. All experimental animals had myocardial lesions, which were confirmed by increased serum levels of $\mathrm{CK}$ and $\mathrm{CK}-\mathrm{MB}$, although there were no alterations in the serum concentration of troponin. Pulmonary hemorrhage was detected in whole lungs and microscopically confirmed by the presence of congested capillaries and erythrocytes in the alveolar parenchyma. In conclusion, $T$. serrulatus venom caused great cardiorespiratory damage to weaned rats.
\end{abstract}

KEY WORDS: Tityus serrulatus, rats, electrocardiography, CK, CK-MB, troponin, pulmonary hemorrhages.

CONFLICTS OF INTEREST: There is no conflict.

\section{CORRESPONDENCE TO:}

MARILIA MARTINS MELO, Escola de Veterinária, Universidade Federal de Minas Gerais, Belo Horizonte, MG, 30.123-970, Brasil. Phone: +55 313409 2229. Fax: +55 313409 2230. Email: mariliamm@ufmg.br. 


\section{INTRODUCTION}

In tropical and subtropical countries, scorpion envenomation is very common and often evolves into a severe condition in children. According to the Brazilian Ministry of Health (1), 10,000 cases of human accidental envenomation by scorpions were recorded in Brazil in 1998; this number increased to 18,000 in 2001 and doubled to 36,000 cases in 2009. In general, these cases were characterized by a total mortality rate of $1.1 \%$, although the rate among children exceeded $10 \%$.

The clinical manifestations of envenomation are attributed to the venom action on ion channels of neuronal membranes and subsequent release of neurotransmitters, especially catecholamines from autonomic nerve terminals. These adrenergic and cholinergic releases produce a systemic response that is characterized by increased levels of different inflammatory mediators (2).

Alterations in the cardiorespiratory system resulting from the toxic effects of catecholamines are of particular significance due to the fatal consequences they may engender. Such manifestations include hypertension followed by hypotensive shock, arrhythmias, tachycardia and/or bradycardia, which may culminate in pulmonary edema (3-7). The action of catecholamines on cardiac tissue is similar to that induced by pheochromocytoma, a tumor that affects the chromaffin cells present in the medulla of the adrenal glands and leads to great concentrations of adrenaline (6, 8).

However, some myocardial lesions have shown to be compatible not only with catecholamine release, suggesting a direct cardiotoxic effect of the scorpion venom (6). Additionally, the heart contractile function was sustained when sympathetic nerve terminals were blocked (9). Respiratory manifestations caused by scorpionism include coughing, sneezing, rhinorrhea, pulmonary rales, dyspnea and pulmonary edema, which may have cardiogenic or non-cardiogenic origin $(10,11)$. Furthermore, pulmonary lesions characterized by bilateral congestion of the capillaries, lung alveoli filled with amorphous and proteinaceous material, and red blood cells in focal areas have been detected following scorpion envenomation (12).

In Brazil, the predominant scorpion species is Tityus serrulatus, especially in urban areas where optimal environmental habits abound (13-15). In view of the high incidence of infant fatality following scorpion envenomation, it is crucial that the cardiorespiratory alterations induced by $T$. serrulatus venom in young individuals can be identified for appropriate clinical treatment. In the present study, the effects of 
experimental envenomation with $T$. serrulatus venom on the cardiorespiratory system of recently weaned rats were evaluated.

\section{MATERIALS AND METHODS}

This research project, which received the protocol number 171/2008, was approved by the Ethical Committee on Animal Experimentation of the Federal University of Minas Gerais (UFMG) on March 14, 2008.

Fifteen recently weaned male Wistar rats with mean weight of $130 \mathrm{~g}$ (range 110-150 g) were supplied by the animal facility of the Institute of Biological Sciences at UFMG. The animals were kept in cages $(40 \times 45 \times 45 \mathrm{~cm})$ under appropriate conditions in the Laboratory of Toxicology of the School of Veterinary Medicine of UFMG and received commercial animal food (Labina ${ }^{\circledR}$, Purina, Brazil) and water ad libitum. Venom was manually extracted from $T$. serrulatus scorpions kindly provided by the Zoonosis Control Center (Ituiutaba, Minas Gerais State, Brazil); then, it was lyophilized and incorporated with ultrapure water at the time of use.

The study animals were distributed into three equal groups $(n=5)$. Rats in the control group (group A) received $400 \mu \mathrm{L}$ ultrapure water as placebo, while those in the experimental groups received $400 \mu \mathrm{L}$ of a solution containing $100 \mu \mathrm{g}$ (group B) or $450 \mu \mathrm{g}$ (group C) scorpion venom; such doses were previously determined in a pilot experiment and were based on the LD50 of $T$. serrulatus venom for rats $(16,17)$. In all cases, administration occurred via subcutaneous injection into the interscapular region using a hypodermic syringe.

Electrocardiography (ECG) was carried out using a model ECG40® instrument (Funbec, Brazil) and traces were recorded on thermal paper (48 mm x $30 \mathrm{~m}$; Controles Gráficos Daru, Brazil) at speeds of 25 and $50 \mathrm{~mm} / \mathrm{s}$ and sensitivities of $\mathrm{N}$ and 2N. ECG electrodes were connected to the animals through disposable acupuncture needles inserted into appropriate sites. Electrocardiograms were obtained prior to the experiment and at 5, 10, 15, 20, 25 and 30 minutes after placebo or venom administration. Throughout the experiment, the animals were maintained under general anesthesia induced by isoflurane inhalation through a Metalvet Plus $®$ anesthetic inhaler (Metalvet, Brazil). Preanesthetic medication to help general anesthesia induction included morphine $(2.5 \mathrm{mg} / \mathrm{kg})$ and diazepam $(2.5$ $\mathrm{mg} / \mathrm{kg}$ ) applied via intramuscular injection (18). 
At 40 min after placebo or venom administration, the animals were anesthetized by means of intramuscular injection of a mixture containing xylazine hydrochloride (10 $\mathrm{mg} / \mathrm{kg}$ ) and ketamine $(75 \mathrm{mg} / \mathrm{kg})$, as recommended by the Ethics Committee on Animal Experimentation, and blood was collected by intracardiac puncture. Blood samples were stored in flasks without anticoagulant. Biochemical profiles of blood from the cardiac muscle were established based on colorimetric analysis of creatine kinase $(\mathrm{CK})$ and $\mathrm{CK}-\mathrm{MB}$ isoenzyme using a Cobas Mira Classic $®$ chemical analyzer (Roche, USA) and commercial kits from Bioclin (Belo Horizonte, Brazil). Semiquantitative analysis of troponin was performed using the immunochromatographic Hexagon Troponin Plus ${ }^{\circledR}$ test (Human International, Germany).

The animals were euthanized by hypovolemia under anesthesia and subjected to necropsy. Hearts and lungs were removed, fixed in $10 \%$ buffered formalin and embedded in paraffin (19). Histological sections (4- $\mu$ m thick) were stained with hematoxylin-eosin (HE) and analyzed under an optical microscope.

The experiment followed a random design. Data were subjected to Lillifors, Kolmogorov-Smirnov and Shapiro-Wilk normality tests. Analysis of variance (ANOVA) was applied to the variables, the mean values of which were compared using the SNK test. Statistical analyses were carried out with the aid of SAS (Cary, USA) and "Sistema para Análises Estatísticas e Genéticas" (20) software.

\section{RESULTS AND DISCUSSION}

Alterations in the ECG traces were observed from five minutes after the envenomation of experimental animals with $T$. serrulatus venom, and such variations were more severe in the later stages of the experiment. The animals of groups $B$ and $\mathrm{C}$ had changes that were compatible with electrolytic imbalance, including increased $T$ wave (Figure 1A) and presence of an rS wave (Figure 1B). Such changes are typically caused by electrolytic, respiratory and gastrointestinal losses.

Scorpion venom is known to produce alterations in the serum concentration of ions resulting from its direct action on ion channels of the plasma membrane. In addition, respiratory and metabolic acidosis, together with increased $\mathrm{H}^{+}$excretion by the stomach, has also been described as a direct effect of envenomation $(6,21,22)$. An rS wave may indicate a modified repolarization axis caused by an increase in the right ventricle, which is directly linked to the pulmonary circulation. This alteration 
suggests that the right ventricle of envenomed animals overworked due to the presence of extensive hemorrhagic pulmonary areas, detected by macroscopic and histopathological examination. Under such circumstances, impaired blood flow could have accounted for the cardiac complications observed.

Additionally, ECG traces revealed the presence of premature ventricular complexes (PVC) (Figure 1) and T waves of varying morphology (data not shown). PVC are impulses generated in the heart ventricles due to the abnormal automaticity of myocytes and may cause direct effects on the cardiovascular system or secondary effects resulting from inadequate tissue perfusion. According to various authors, PVC are associated with myocardial abnormalities caused by catecholamine and cytokine release following scorpion envenomation (6, 9, 22-27).
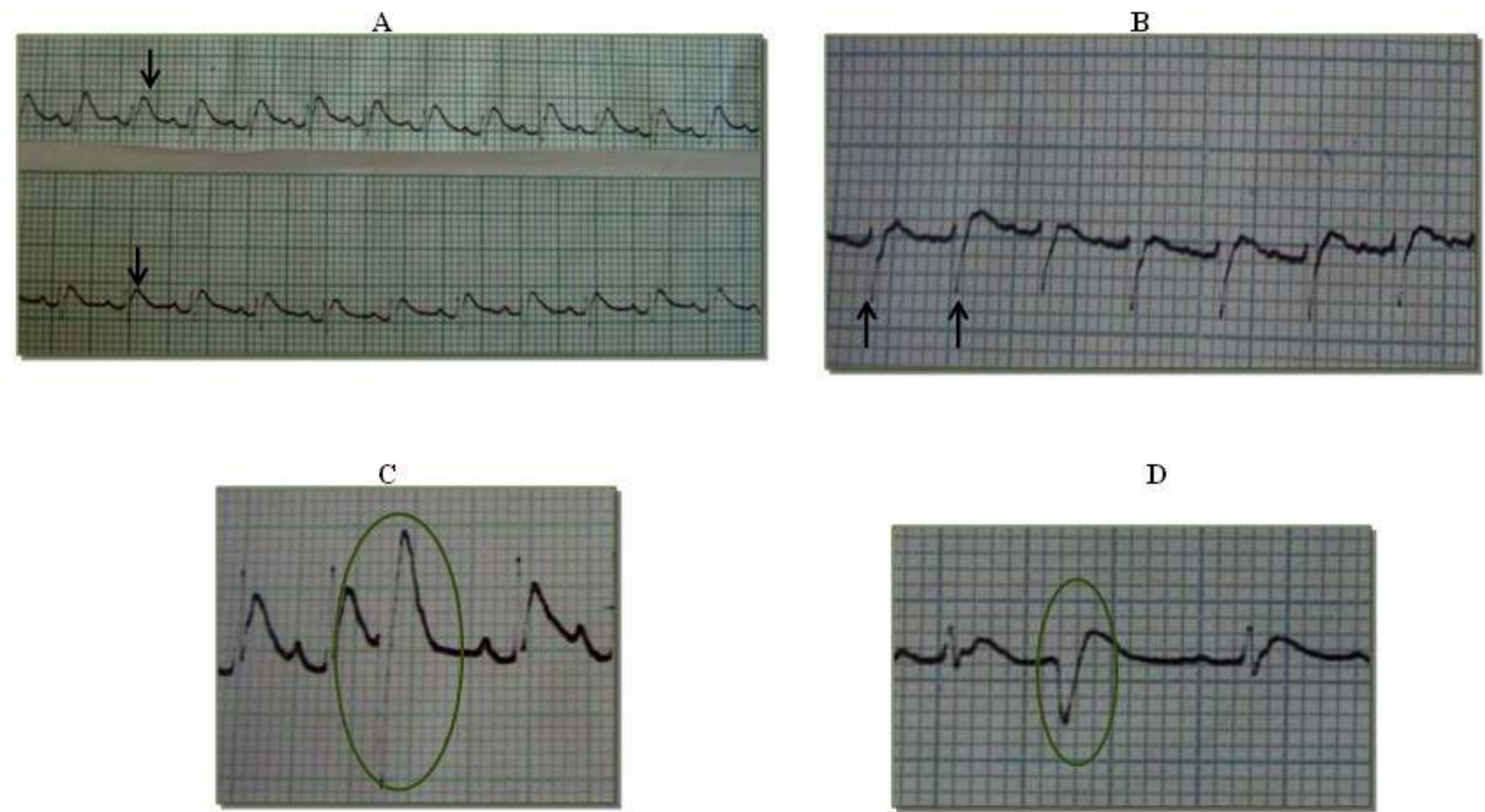

D

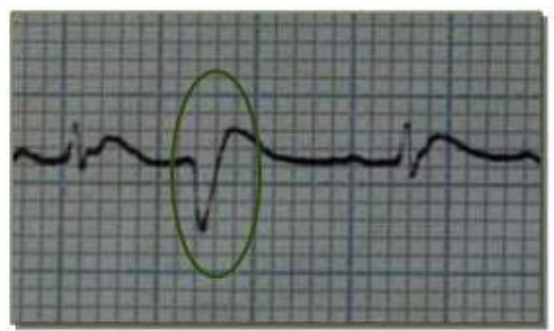

Figure 1. Electrocardiographic traces for animals subjected to experimental envenomation using Tityus serrulatus venom; $(\mathbf{A})$ increased $T$ wave at ten minutes for animals in both envenomed groups, (B) presence of an rS wave at ten minutes for animals in groups B and C, and (C-D) premature ventricular complexes at 15 and 20 minutes for all envenomed animals (PVC; circled). Speed of $50 \mathrm{~mm} / \mathrm{s}$ and sensitivity of $2 \mathrm{~N}$. 
Initially, all experimental animals had a discreet increase in the cardiac rate [heart rates rising from 400 beats per min (bpm) to 460-480 bpm], which was caused by pain stimulus and adrenaline release, a positive chronotropic effect. At 25 minutes after the venom administration, envenomed animals had accentuated bradycardia and inverted T wave (Figure 2A), and their heart rate fell typically to 200-240 bpm. Bradycardia was caused by increased vagal tone resulting from cholinergic release, together with the acute renal failure (ARF) developed by the animals (demonstrated by laboratory analysis). Hypercalcemia, which may be intensified by the low renal perfusion typical of ARF, also contributes to bradycardia since it depresses the cardiac conduction. At 30 minutes after envenomation, bradycardia intensified, falling to $80-140 \mathrm{bpm}$ (Figure 2B), as demonstrated by third-degree atrioventricular (AV) blocks (data not shown), which reflected a serious hemodynamic disorder that was characterized by the complete dissociation between atrial and ventricular beats caused by cell inhibition or inactivity in the AV junction or in the right and left bundle branches. Escape rhythm was also detected, indicating that the frequency of the sinoatrial (SA) node was reduced or even stopped, and the activity of AV junction or ventricle pacemakers assumed the cardiac rhythm. Escape rhythm is associated with bradycardia and electrolytic imbalance, as observed in scorpion envenomation (Figure 2B). 
A
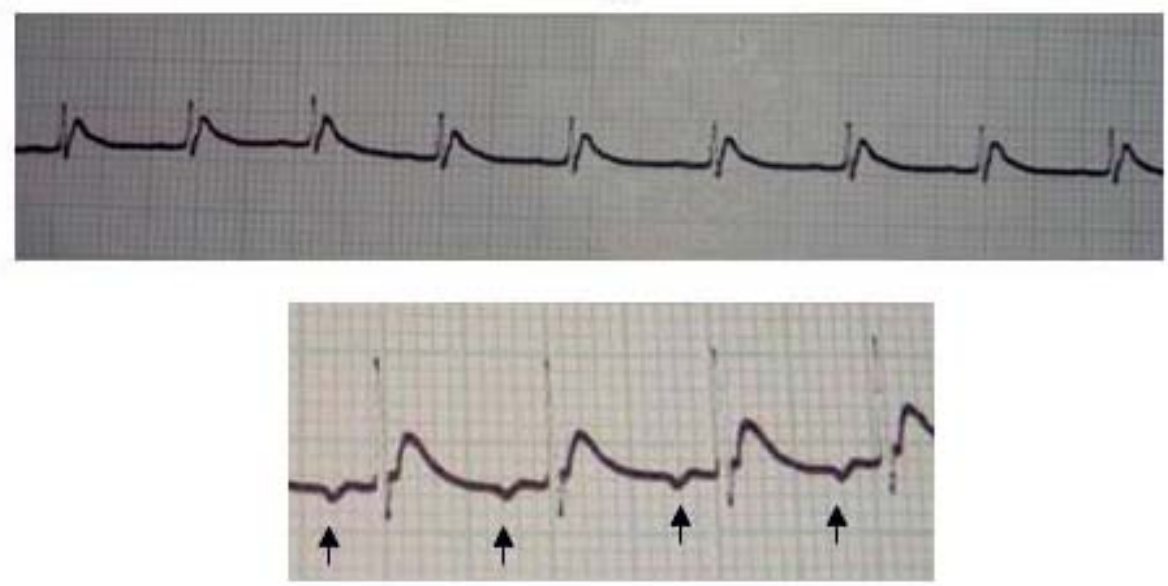

B

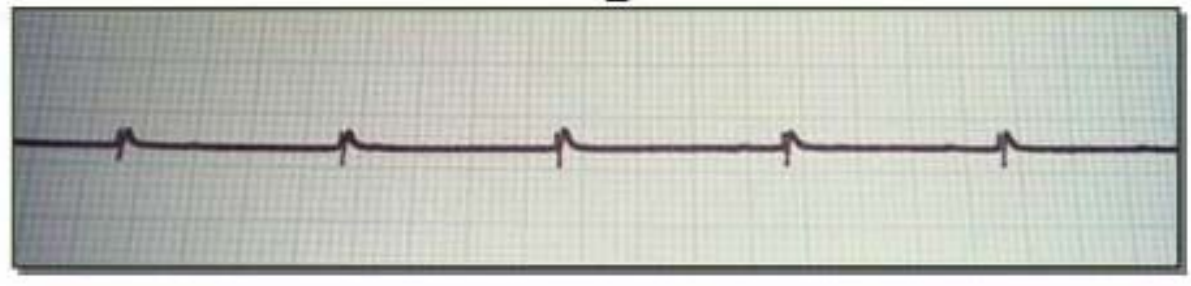

Figure 2. Electrocardiographic traces of animals in group $C$, which were subjected to experimental envenomation using Tityus serrulatus venom; (A) bradycardia at 25 minutes and inverted $\mathrm{P}$ wave (arrowed), and (B) accentuated bradycardia at 30 minutes. Speed of $25 \mathrm{~mm} / \mathrm{s}$ and sensitivity of $\mathrm{N}$.

Sinus arrhythmia was observed together with inversion and increased amplitude of $\mathrm{T}$, $P$ and $Q$ waves in dogs subjected to experimental envenomation using $T$. serrulatus venom (28). Similarly, sinus tachycardia, ectopic pacemaker, ventricular extrasystoles and alterations in the ST segment were observed in a dog accidentally envenomed by $T$. bahiensis (29). The ECG traces obtained in the present study were comparable with those for scorpionism in general. However, the changes in ECG parameters were more severe among the animals in group $C$, which received a lower venom dose.

Cardiac muscle function was assessed by quantifying the activities of serum CK, CKMB isoenzyme and troponin I following envenomation (Table 1). CK levels in the experimental animals of groups $B$ and $C$ were significantly higher $(P<0.05)$ than that of group $A$ (control), indicating that the venom induced muscle lesions. CK-MB activities in the animals of groups $B$ and $C$ were similar and high, compared to the 
control group; however, such increases were only statistically valid for group $\mathrm{C}$ due to an unusually low activity presented by one animal in group $B$.

Previous studies have shown that lesions in the heart are a consequence of catecholamine overload. Indeed, inhibition of ion channels by scorpion venom triggers the release of neuronal and adrenal catecholamines, leading to increased oxygen consumption by the myocytes, myocardium hypoxia and tissue degeneration (30). Moreover, a study using electron microscopy identified myocardial anomalies that were different from those attributed to excessive catecholamine levels (6). Although CK and CK-MB activities peaked later than the blood collection time in the present study, the increased levels determined for both enzymes indicate an acute action of the venom on the hearts of newly weaned rats (31). 
Table 1. Activities of creatine kinase (CK) and cardiac isoenzyme (CK-MB) in the serum of individual animals in the control group A (injected with $400 \mu \mathrm{L}$ ultrapure water) and in the experimental groups B (injected with $400 \mu \mathrm{L}$ of a solution containing $100 \mu \mathrm{g}$ scorpion venom) and C (injected with $400 \mu \mathrm{L}$ of a solution containing $450 \mu \mathrm{g}$ scorpion venom)

\begin{tabular}{|c|c|c|c|c|}
\hline Group & Animals & CK (U/L) & CK-MB (U/L) & Troponin \\
\hline \multirow{6}{*}{ A } & 1 & 1613 & 591 & Negative \\
\hline & 2 & 1748 & 461 & Negative \\
\hline & 3 & 1293 & 232 & Negative \\
\hline & 4 & 907 & 223 & Negative \\
\hline & 5 & 904 & 560 & Negative \\
\hline & Mean & $1293 \pm 390^{a}$ & $413 \pm 176^{a}$ & \\
\hline \multirow{6}{*}{ B } & 1 & 1480 & 400 & Negative \\
\hline & 2 & 5060 & 1160 & Negative \\
\hline & 3 & 2920 & 920 & Negative \\
\hline & 4 & 5620 & 1460 & Negative \\
\hline & 5 & 3770 & 3540 & Negative \\
\hline & Mean & $3770 \pm 1662^{b}$ & $1496 \pm 1206^{\mathrm{ab}}$ & \\
\hline \multirow{6}{*}{ C } & 1 & 4340 & 2020 & Negative \\
\hline & 2 & 4120 & 1140 & Negative \\
\hline & 3 & 1260 & 740 & Negative \\
\hline & 4 & 5860 & 1500 & Negative \\
\hline & 5 & 8240 & 2060 & Negative \\
\hline & Mean & $4764 \pm 2557^{b}$ & $1492 \pm 568^{b}$ & \\
\hline
\end{tabular}

Mean values ( \pm standard error) are shown for the five animals in each group. Within each column, mean values followed by different lowercase letters are significantly different at $P<0.05$ according to analysis of variance and SNK test

Although increased levels of troponin I (> 50-fold) have been reported for humans following accidental scorpion stings, no change in the levels of this protein was 
observed for the experimental animals in the present study $(11,12,32)$. However, this result is not entirely reliable since the amounts of released troponin I could have been below the detection limits $(0.5 \mathrm{ng} / \mathrm{mL})$ of the semiquantitative test employed.

Macroscopically, extensive diffuse hemorrhagic areas were found in all lung lobes of the animals in experimental groups $B$ and $C$ (Figure $3-A$ to $C$ ), although no noteworthy alterations were observed in their hearts. Histological analysis of the lung tissue of envenomed animals showed moderate congestion of the alveolar capillaries and large quantities of erythrocytes distributed diffusely in the interstitial and intraalveolar spaces (Figure $3-D$ and $E$ ). Such hemorrhagic indications demonstrate the direct action of the venom. Histological analysis of the heart tissue from experimental animals revealed no histopathological alterations.

A
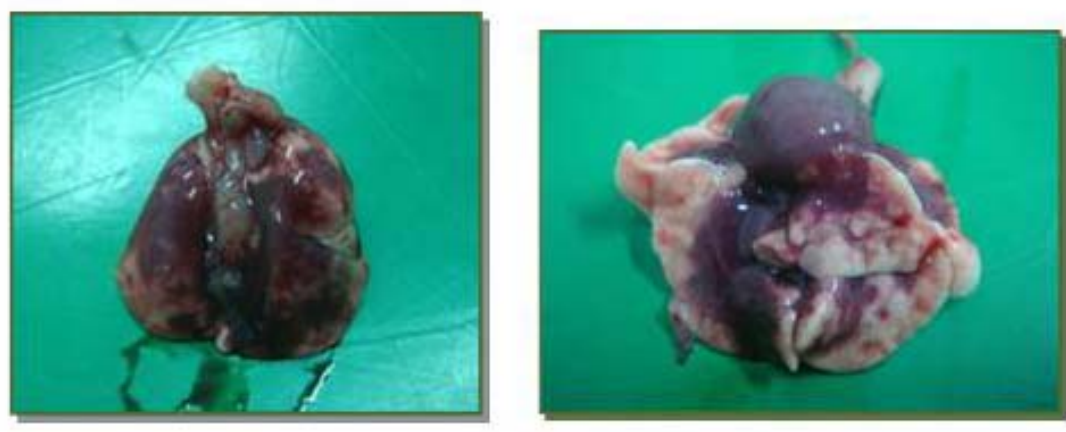

C

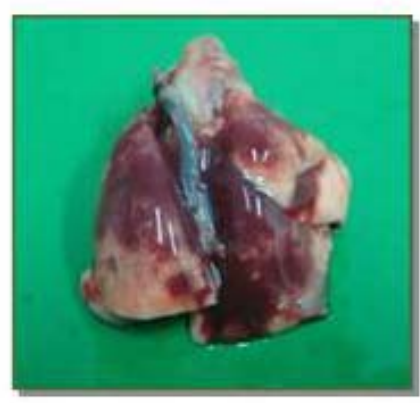

$\mathrm{D}$

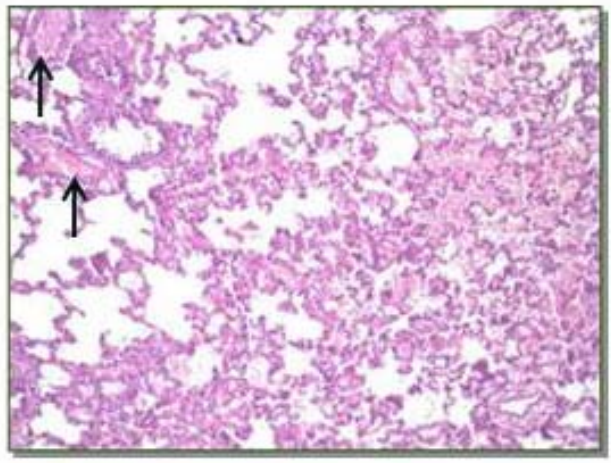

E

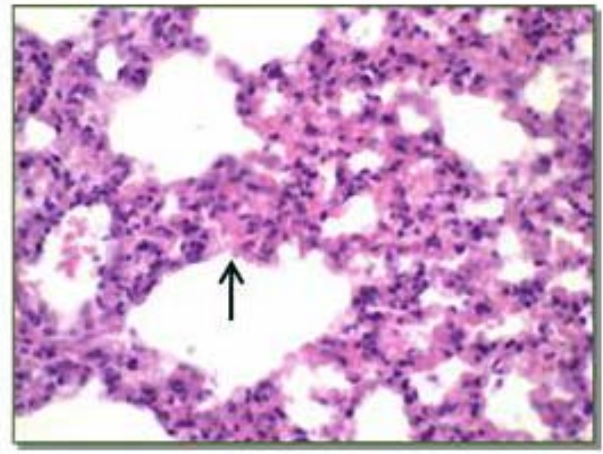

Figure 3. Lungs of the animals in groups $B$ and $C$, which were subjected to experimental envenomation using Tityus serrulatus venom; (A to $\mathbf{C}$ ) extensive hemorrhagic areas in the whole organs, and histological sections revealing (D) capillary congestion (arrowed) and (E) presence of erythrocytes in the parenchyma (arrowed). 
Kinetic studies concerning the distribution of $T$. serrulatus venom, determined by ELISA, have demonstrated the great affinity of toxins for heart, lungs, spleen and serum $(33,34)$. Venom levels were maximal at 30 minutes after administration; after two hours of experiment these concentrations plummeted, and no venom could be detected in any tissue at eight hours after envenomation. Radioactivity tracer experiments using technetium-99 showed that Mesobuthus tamulus venom could be detected in the lungs of rats at five minutes after envenomation (35). Such a rapid distribution of the venom in the lungs, together with intense pulmonary hemorrhage, support the hypothesis that the venom has a direct action on organs and ultimately leads to development of pulmonary edema and impairment of the cardiac function, as observed in classical scorpion envenomation syndrome.

Although cardiac lesions could not be detected by optical microscopy, the molecular structure of the tissue was affected, which was demonstrated by the significant increases in CK and CK-MB activities. Several researchers have explained the severity of scorpion envenomation in children by demonstrating the occurrence of myocarditis, high blood pressure, tachyarrhythmia followed by bradycardia, serious pulmonary edema, congestive heart failure and respiratory insufficiency in victims (10, 32, 36-38). A study evaluated 41 Egyptian children who were accidentally envenomed by scorpions and reported the occurrence of severe clinical manifestations, in addition to myocarditis (17 patients), increased CK and CK-MB activities, increased troponin-I levels, and a mortality rate of $12.5 \%$ (23). The influence of age on the pharmacokinetics and biodistribution of isolated toxins from $T$. serrulatus venom in rats has been investigated and the results indicate that toxin distribution and maximum concentration in the brain, heart and liver occur very rapidly in young animals compared to adult ones, whereas clearance and elimination are slower $(39,40)$. The results of the present study corroborate previous findings regarding the susceptibility of young animals to scorpion venom.

\section{CONCLUSIONS}

T. serrulatus venom, at doses of 100 and $450 \mu \mathrm{g} / \mathrm{animal}$, induced acute alterations in the electrocardiographic, biochemical and histopathological parameters of recently weaned rats, indicating the great vulnerability of young animals to scorpion envenomation. 


\section{REFERENCES}

1. Brasil. Ministério da Saúde. Portal da saúde. Brasília, DF: Secretaria do Ministério da Saúde. [update 2010 Feb 5; cited 2007 Feb 5]. Available from: http://portal.saude.gov.br/portal/arquivos/pdf/casos ac escorpioes bra 00a09 tabel a.pdf.

2. D'Suze G, Moncada S, González C, Sevcik C, Aguilar V, Alagón A. Relationship between plasmatic levels of various cytokines, tumor necrosis factor, enzymes, glucose and venom concentration following Tityus scorpion sting. Toxicon. 2003;41(3):367-75.

3. Freire-Maia L, Campos JA. On the treatment of the cardiovascular manifestations of scorpion envenomation. Toxicon. 1987;25(1):125-30.

4. Gueron M, Ovsyshcher I. What is the treatment for the cardiovascular manifestations for scorpion envenomation? Toxicon. 1987;25(1):121-4.

5. Gueron M, Ilia R, Sofer S. The cardiovascular system after scorpion envenomation. A review. J Toxicol Clin Toxicol. 1992;30(1):245-58.

6. Ismail M. The scorpion envenoming syndrome. Toxicon. 1995;33(7):825-58.

7. Ismail M, Abd-Elsalam MA. Are the toxicological effects of scorpion envenomation related to tissue venom concentration? Toxicon. 1988;26(3):233-56.

8. Faiçal S, Shiota D. Feocromocitoma: atualização diagnóstica e terapêutica. Rev Assoc Med Brasil. 1997;43(3):237-44.

9. Teixeira Jr AL, Fontoura BF, Freire-Maia L, Machado CRS, Camargos ERS, Teixeira MM. Evidence for a direct action of Tityus serrulatus scorpion venom on the cardiac muscle. Toxicon. 2001;39(5):703-9.

10. Campos JA, Silva AO, Lopez M, Freire-Maia L. Signs, symptoms and treatment of severe scorpion sting in children. Toxicon. 1979;17(1):1-21.

11. Cupo P, Azevedo-Marques MM, Hering SE. Escorpionismo. In: Cardoso JLC, editor. Animais peçonhentos no Brasil: biologia clínica e terapêutica dos acidentes. São Paulo: Salvier; 2003. 198-208 p.

12. Cupo P, Jurca M, Azevedo-Marques MM, Oliveira JSM, Hering SE. Severe scorpion envenomation in Brazil: clinical, laboratorial and anatomopathological aspects. Rev Inst Med Trop São Paulo. 1994;36(1):67-76.

13. Fukuhara YDM, Dellalibera-Joviliano R, Cunha FQC, Reis ML, Donadi EA. The kinin system in the envenomation caused by the Tityus serrulatus scorpion sting. Toxicol Appl Pharmacol. 2004;196(3):390-5. 
14. Lourenço WR, Cloudsley-Thompson JL, Cuellar O, Von Eickstedt VRD, Barraviera B , Knox MB. The evolution of scorpionism in Brazil in recent years. J Venom Anim Toxins. 1996;2(2):121-34.

15. Freire-Maia L, Campos JA, Amaral CF. Approaches to the treatment of scorpion envenoming. Toxicon. 1994;32(9):1009-14.

16. Nunan EA, Cardoso VN, Moraes-Santos T. Lethal effect of the scorpion Tityus serrulatus venom: comparative study on adult and weanling rats. Rev Bras Ciênc Farm. 2001;37(1):39-44.

17. Vasconcelos F, Sampaio SV, Garófalo MA, Guimarães LF, Giglio JR, Arantes EC. Insulin-like effects of Bauhinia forficata aqueous extract upon Tityus serrulatus scorpion envenoming. J Ethnopharmacol. 2004;95(2-3):385-92.

18. Flecknell P. Laboratory animal anaesthesia. $2^{\text {nd }}$ ed. San Diego: Academic Press; 1996. 274 p.

19. Prophet EB, Mills R. Afip laboratory methods in histotechnology. Washington, DC: American Registry of Pathology; 1992. 278 p.

20. Fundação Arthur Bernardes. Sistema para análises estatísticas e genéticas (SAEG). Version 9.1. Viçosa: Universidade Federal de Viçosa; 2007.

21. El-Asmar MF. Metabolic effect of scorpion venom. In: Tu AT, editor. Handbook of natural toxins, insects, poisons, allergens and other invertebrate venoms. New York, NY: Marcel Dekker; 1984. 551-75 p. 2 vol.

22. Meki ARMA, Mohey El-Dean ZM. Serum interleukin-1 $\beta$, interleukin-6, nitric oxide and a1-antitrypsin in scorpion envenomed children. Toxicon. 1998;36(12):1727-48.

23. Magalhães MM, Pereira ME, Amaral CF, Rezende NA, Campolina D, Bucaretchi $\mathrm{F}$, et al. Serum levels of cytokines in patients envenomed by Tityus serrulatus scorpion sting. Toxicon. 1999;37(8):1155-64.

24. Meki AR, Mohamed ZM, El-Deen HM. Significance of assessment of serum cardiac troponin I and interleukin-8 in scorpion envenomed children. Toxicon. 2003; 41(2):129-37.

25. Murthy KR, Hase NK. Scorpion envenoming and the role of insulin. Toxicon. 1994; 32(9):1041-4.

26. Raab W. Key position of catecholamines in functional and degenerative cardiovascular pathology. Am J Cardiol. 1960;5(1):571-8.

27. Sofer S, Gueron M, White RM, Lifshitz M, Apte RN. Interleukin-6 release following scorpion sting in children. Toxicon. 1996;34(3):389-92. 
28. Cordeiro FF, Sakate M, Fernandes V, Cuyumjian PR. Clinical and cardiovascular alterations produced by scorpion envenomation in dogs. J Venom Anim Toxins incl Trop Dis. 2006;12(1):19-43.

29. Cardoso MJL, Sakate M, Ciampolini $P$, Moutinho FQ, Cherubini AL. Envenomation by scorpion in dog - case report. J Venom Anim Toxins incl Trop Dis. 2004;10(1):98-105.

30. Possani LD, Becerril B, Delepierre M, Tytgat J. Scorpion toxins specific for $\mathrm{Na}^{+}-$ channels. Eur J Biochem. 1999;264(2):287-300.

31. Thrall MA. Veterinary hematology and clinical chemistry. Philadelphia: Lippincott Willians \& Wilkins; 2004. 518 p.

32. Bucaretchi F, Baracat ECE, Nogueira RJN, Chaves A, Zambrone FAD, Fonseca MRCC, Tourinho FS. A comparative study of severe scorpion envenomation in children caused by Tityus bahiensis and Tityus serrulatus. Rev Inst Med Trop São Paulo. 1995;37(4):331-6.

33. Revelo MP, Bambirra EA, Ferreira AP, Diniz CR, Chávez-Olórtegui C. Body distribution of Tityus serrulatus scorpion venom in mice and effects of scorpion antivenom. Toxicon. 1996;34(10):1119-25.

34. Santana GC, Freire AC, Ferreira AP, Cháves-Olórtegui C, Diniz CR, Freire-Maia L. Pharmacokinetics of Tityus serrulatus scorpion venom determined by enzymelinked immunosorbent assay in the rat. Toxicon. 1996;34(9):1063-6.

35. Murugesan S, Murthy KRK, Noronha OPD, Samuel AM. Tc 99m-Scorpion venom: labelling, biodistribution and scintiimaging. $\mathrm{J}$ Venom Anim Toxins. 1999;5(1):35-46.

36. Amaral CF, Lopes JA, Magalhães RA, de Rezende NA. Electrocardiographic, enzymatic and echocardiographic evidence of myocardial damage after Tityus serrulatus scorpion poisoning. Am J Cardiol. 1991;67(7):655-7.

37. El-Amin EO. Issues in management of scorpion sting in children. Toxicon. 1992; 30(1):111-5.

38. Sofer S, Gueron M. Respiratory failure in children following envenomation by the scorpion Leiurus quinquestriatus: hemodynamic and neurological aspects. Toxicon. 1988;26(1):931-9.

39. Nunan EA, Moraes MF, Cardoso VN, Moraes-Santos, T. Effect of age on body distribution of tityustoxin from Tityus serrulatus scorpion venom in rats. Life Sci. 2003;73(3):319-25. 
Pinto MCL et al. Cardiorespiratory evaluation of juvenile rats experimentally envenomed with Tityus serrulatus venom. J Venom Anim Toxins incl Trop Dis. 2010;16(2):267

40. Nunan EA, Arya V, Hochhaus G, Cardoso VN, Moraes-Santos T. Age effects on the pharmacokinetics of tityustoxin from Tityus serrulatus scorpion venom in rats. Braz J Med Biol Res. 2004;37(3):385-90. 